ments on loose contacts, that I thought of the experiment in question. My idea was to replace his heated point of metal by a continuous portion of the circuit which should act in the same manner. It was obvious that this part must be of small diameter to secure resistance enough to make the extension of the wirc due to the variation of the heating effect sensible; and to insure that the cooling should be rapid enough to allow a musical nute to be produced.

I liad reason beforehand to believe that the sccond condition could be fulfilled in practice; because I had found in my experi. ments on Ohm's Law (Reports, British Association, 1876, p. 58, ct $s c q$.) that, when currents of different strengths alternated very rapidly in a fine wire, the cooling was so rapid that the resistance was sensibly greater during the passage of the strong current than it was during the passage of the weaker.

The accompanying figure represents the apparatus with which I worked. I generally used a microphone attached to a violin, belonging to $\mathrm{Mr}$. Blyth, for a transmitter. In this way music was reproduced so as to be audible all over Prof. 'Tait's large class-room. For reproducing articulate specch I have found a small mica diaphragm, like that used by Edison, Blyth, and others, best; words spoken to the violin are reproduced in this way quite intelligibly, but as I do not possess a gocd microphone transmitter, I have not experimented much in this dircction.

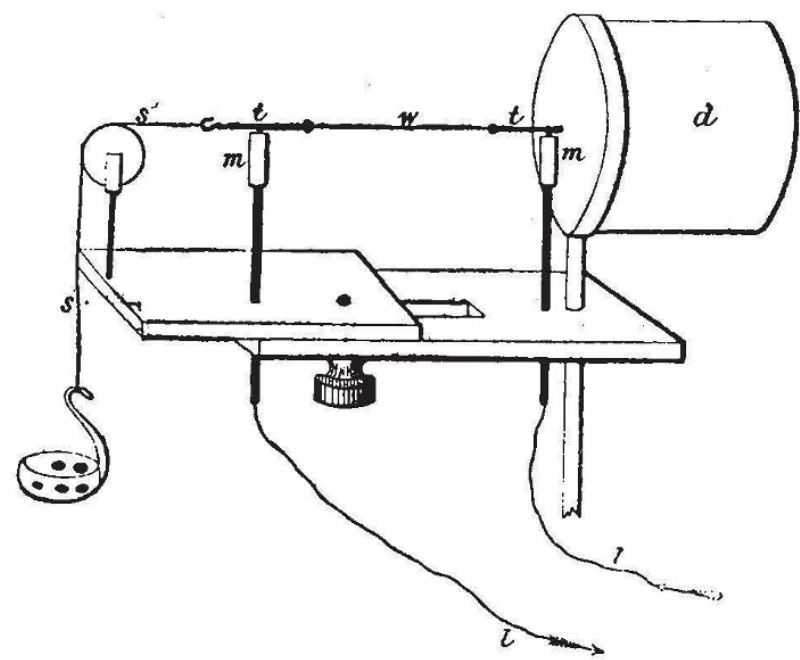

$3 v$, fine wire : $t t$, thicker copper terminals ; $m m$, mercury cups over which $t t$ pass; $s$, , string keft tight by small load; $t l$, line wires to micro. $t$ t pass; $s$, string kept tight by small had ; $l l$,
phone $d$, drum head which distributes the scund.

So far as the limited supply of fine wire permitted, I bad arrived substantially at the same results as Mr. Precce regarding the length and tension of the wire. My best results were got with a very fine silver-palladium wire given me by Prof. 'Tait ; with it I could see the string S S move in time with the swell of the music. I also used a thicker and shorter platinum wire, heated by the current to a dull red, during silence; it was beautiful to see this wire burst into a bright glow when there came a prolonged note, more especially a high one.

Dr. Ferguson, in the paper above referred to, regards these effects as not due to heating (although he seems to think they follow the same law), but as being molecular in some other sense not very clearly defined. Except in the case of iron, ${ }^{1}$ I do not see at present any necessity for so regarding them. The fact that induction-currents of small heating effect will produce them is not conclusive; for it must be remembered that it is not the whole heating effect, but the variation of it during a very short interval that is in question, and some calculations from rough data in my possession have led me to think that there would he no inconsistency in explaining Dr. Ferguson's ticls and the speech and music in Mir. Preece's experiment and my own as due to the same cause. I think also that it is quite possible that

'Iron may be anomalcus on acccunt of :ts powerful magnetic prepcries; and Prof. Tait has suggested that, at a certain high temperature, it may, fur

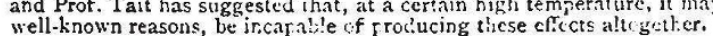

we might be able to hear ticks in a wire far too thick for the reproduction of music.

I have begun some experiments with a view to throw some light on questions of this kind. Possibly in the meantime Dr. Ferguson, Mr. Preece, or some other experimenter may be able to produce facts that settle the matter beyond the possibility of cloubt.

15, Chalmers Street, Edinburgb, June 12

G. Chrystal

\section{The Aurora Borealis and its Colours}

Ix reference to Mr. Backhouse's letter last week (p. I45) we have $n$ wherc stated that "similarity in colour in electric discharges is sufficient to indicate similarity of constitution, even when their spectra are quite unlike" If Mr. Backhouse will again read our paper on the Auroræ, he will see that we say that in the same gas the colour of the discharge varies with the degree of exhaustion. In the Phil. Trans., 1878, part I, we have shown also that in the same gas at the same pressure the colour of the discharge varies with the amount of current; at pp. $180-181$, for example, the strata in hydrogen at a pressure of $\mathrm{r} \cdot 2 \mathrm{~mm}$., $1579 \mathrm{M}$, were of a cobalt blue with a current of $0.019940 \mathrm{~W}$, and pink with a current of $0.008504 \mathrm{~W}$. In the index at p. 239 are given several references to the same pheno. mena; and at p. 240 references are given to a number of observations on the "spectra of strata and of glow on terminals."

It is very difficult to say for certain whether the red is bolow or above the green in aurora displays, by eye estimation; for although apparently ahove it may be really below. We adhere to our opinion that the rerl is at the lower level.
73, Tortland Place, IV.
IIUGO MÜLLER

WARREN DE I.A RUE.

On some Points Connected with Terrestrial Magnetism

IN NAture, vol. xxii. p. I47, our friend Prof. Balfour Stewart makes the following statement in paragraph $\gamma$ :-

"A bove this again we have the lower strata of the atmosphere, which are non-conductors, while above this we have the upper strata, which are conductors."

We venture to think that our researches prove that air cannot, at any degree of attenuation, he considered as a conductor of electricity in the ordinary acceptation of the term.

In the Phil. Trans., Part I. p. 168, after citing a number of experiments bearing on this puint, we say:- "These olservations show clearly that the discharge through rarefied gases cannat be at all analogrius to conduction through metals; for a wire having a given difference of potential between its ends can permit onc-and only one-current to pass; whereas we see that with a given difference of potential between the terminals of a vacuum tube carrents of strengths varying from 1 to $r 35$ can flow. We arc therefore led to the conclusion that the disclarge in a vacuum tube does not differ materially from that in air and other gases at ordinary atmospheric pressure, that it is, in fact, a disruptive discharge."

In Part IIl. of our rescarches (an abstract of part of which appears in the same number of NATURE), Phil. Trans., vol. clxxi. p. 82 , we sum up a scrics of experiments on the electric discharge in various gases by stating that the same law holds good for a constant pressure and varying distance between flat terminals as for a constant distance and varying pressure, the obstacle in the way of a discharge being, up to a certain point, as the number of molccules intervening between the terminals.

The hyperbolic curves laid down to represent the observations in each case are perfectly continuous, and show no break from the condition of a non-conductor to that of a conductor.

June 21

WARREN DE I.A RUE HUgo MÜI.LER

\section{Calcareous Concretions in Timber}

I. NATURF, vol, xxi, p. 376, I observe that in a remark of the reviewer, and $2 \mathrm{Iso}$ in an extract from Mr. Ball's "Jungle Life in India," the occurrence of concretions of lime in trees is spoken of as a rare and nuvel phenomenon. That Terminalia tomentosa contains calcareous matter has long been known to natives, and a reference to Tennent's "Ceylon," i. 99, will show that they make a practical use of their knowledge by using the ashes of the bark as a substitute for lime, to chew with betel. Another southern tree which contains an alkali in its bark is Aviscnn: tomentosa. It generally gruws along the margins of backwaters, 